VARIA

\title{
Karol Wojtyla e os níveis de sentido da regra de ouro
} Karol Wojtyla and the levels of meaning of the golden rule

\author{
* Sergio de Souza Salles \\ ** Carlos Frederico Gurgel Calvet da Silveira
}

\begin{abstract}
Resumo: A regra de ouro, o princípio ético segundo o qual devemos fazer aos outros o que nós queremos que nos façam, é também conhecida na tradição cristã como regra de amor ao próximo. O objetivo do presente artigo é examinar a relação entre dois níveis de sentido da regra de ouro nas investigações filosóficas de Karol Wojtyla, anteriores ao seu pontificado. Uma vertente do atual debate sobre a regra de ouro diz respeito às suas raízes antropológicas e ao seu sentido ético. A abordagem filosófica de Karol Wojtyla da regra de ouro perpassa tanto a investigação de suas raízes antropológicas quanto de suas exigências éticas. Com efeito, há um sentido pré-ético da regra de ouro em Karol Wojtyla, que está vinculado à sua abordagem fenomenológica da pessoa humana e da vida em comunidade. Nesse nível, a regra de ouro é descrita a partir da lógica da autorrealização, que manifesta o valor personalista da ação humana. Por outro lado, há também um segundo sentido propriamente ético da regra de ouro, graças ao qual desenvolve sua perspectiva da doação de si como condição da realização de si mesmo. Nessa perspectiva wojtyliana, o que torna uma regra moral áurea é a sua capacidade de integrar e complementar a busca pela própria realização com a realização do outro mediante a doação de si mesmo.
\end{abstract}

Palavras-chave: Karol Wojtyla. Regra de ouro. Autorrealização. Participação. Autodoação.

Abstract: The golden rule, the ethical principle that we should do to others what we want others to do to us, is known also in Christian tradition as the rule of love of neighbor. The aim of this paper is to inquire the relationship between two levels of meaning of the golden rule according to Karol Wojtyla's philosophical investigations, prior to his pontificate. One strand of the actual debate on the golden

* Doutor em Filosofia pela PUC-RJ. Coordenador Adjunto do Mestrado em Direito da UCP. Professor Adjunto da PUC-RJ. <sallesfil@gmail.com>.

* * Doutor em Filosofia pela Pontificia Università San Tommaso (Roma). Professor do Mestrado em Direito da UCP. Professor Adjunto da PUC-Rio. <carlos.silveira@ucp.br>. 
rule concerns its anthropological roots and ethical meaning. Karol Wojtyla's philosophical approach to the golden rule involves both the investigation of its anthropological roots and its ethical requirements. Indeed, there is a pre-ethical sense of the golden rule in Karol Wojtyla, which is linked to his phenomenological approach to human person and life in community. At this level, the golden rule is described from the perspective of the self-fulfillment logic, which manifests the personalist value of human action. On the other hand, there is also a second sense, properly ethical, of the golden rule, thanks to which developed his perspective of self-donation as a condition for self-fulfillment. In this wojtylian perspective, what makes golden a moral rule is its ability to integrate and complement the search for self-realization with the fulfillment of another through the gift of oneself.

Keywords: Karol Wojtyla. Golden rule. Self-fulfillment. Participation. Selfdonation.

\section{Introdução}

$\mathrm{N}$ a tradição cristã medieval, a máxima "ame o próximo como a ti mesmo" foi conhecida como regra de amor ao próximo ("regula dilectionis proximi"). Da Patrística à Escolástica, os autores cristãos referiram-se à regra de amor ao próximo como um princípio prático pertencente à lei natural e à lei revelada. ${ }^{1} \mathrm{Na}$ tradição moderna, sobretudo a partir do século XVII, a máxima "ame o próximo como a ti mesmo" passou a ser conhecida como preceito áureo ou regra de ouro, sendo, frequentemente, identificada como um princípio da lei natural.

No século XVIII, a crítica filosófica à regra de ouro como princípio moral universal foi desenvolvida por Kant, especialmente na Fundamentação da Metafísica dos Costumes, a partir da distinção entre o amor patológico e o prático que, por seu turno, depende da avaliação moral da regra de ouro nos termos do imperativo categórico, graças ao qual o mandamento de amor ao próximo torna-se um dever incondicional. Para Kant, sem a devida derivação do imperativo categórico, o mandamento de amor ao próximo seria incapaz de ser por si mesmo um princípio prático universalmente válido para a razão humana.

A respeito da identificação da regra de ouro como princípio ético e teológico na tradição cristã medieval, confira: WATTLES, Jeffrey. The Golden Rule. New York: Oxford University Press, 1996, p. 52-76; NEUSNER, J. \& CHILTON, B. The Golden Rule: the ethics of reciprocity in world religions. London/New York: Continuum, 2008, p. 88-98. Para uma análise sobre a interpretação de Tomás de Aquino da regra de ouro, confira: SALLES, S.S.; OLIVEIRA, M. M.; SILVA, J. A. do N. "Lei natural e regra de ouro em Tomás de Aquino". Aquinate, 15 (2011), p. 90-115. 
Uma das principais tentativas de reabilitação filosófica do mandamento do amor ao próximo a partir de uma ética personalista foi desenvolvida por Max Scheler. Para o autor de $O$ formalismo na ética e a ética material dos valores, o amor ao próximo não pode ser objeto de um mandamento, nem tampouco derivado de um dever incondicional. Com efeito, Scheler concebe o amor como um ato puramente espontâneo, emocional, suscitado do interior e não do exterior, pelo qual a pessoa encontra e manifesta o mundo dos valores. Ao compreender o mandamento ou o dever moral como uma imposição extrínseca e contrária à dinâmica interior e espontânea do amor, Scheler defende que o mandamento do amor ao próximo não é propriamente moral, mas sim superior à moral no sentido de propiciar a abertura afetiva do si mesmo em relação ao valor pessoal do próximo.

A questão da possibilidade de uma mediação entre o valor e a obrigação, ou ainda entre o amor e o dever, ocupou de maneira especial as reflexões de Karol Wojtyla, que procurou interpretar a regra de ouro justamente nos termos de um duplo sentido, capaz de reestabelecer o elo perdido na modernidade entre o valor e a obrigação, entre o amor e o dever.

Um olhar atento às obras do período anterior ao seu pontificado é capaz de manifestar pelo menos duas aproximações ao tema transversal do amor ao próximo nas obras de Karol Wojtyla. A primeira consiste na investigação do sentido pré-ético da regra de ouro, enquanto a segunda desenvolve-se a partir da interrogação do sentido propriamente ético e moral da regra. Essas duas aproximações encontram-se desde Max Scheler e a Ética Cristã, obra publicada em 1959, até Pessoa e Ato, publicada em 1969, incluindo-se aqui também os artigos da primeira metade da década de setenta, dedicados ao desenvolvimento de sua filosofia da pessoa humana e de sua ética cristã. Em ambas as aproximações teoréticas ao problema da regra de ouro, é possível perceber o esforço de Karol Wojtyla em dialogar a partir das reflexões filosóficas modernas de Kant e Scheler, procurando justificar a validade ética e moral da regra de ouro a partir dos pressupostos de sua própria filosofia personalista.

Duas hipóteses interpretativas acompanham a presente reflexão sobre os dois sentidos da regra de ouro no pensamento de Karol Wojtyla. A primeira sustenta que há um caráter mediador no duplo sentido da regra de ouro em Wojtyla, já que ela funciona teoricamente como uma fórmula de transição entre o valor personalista e o valor moral da ação junto com os outros. A segunda propõe que a regra de ouro, justamente por suas raízes antropológicas e seu apelo ético, permite conciliar duas lógicas aparentemente opostas: a da autorrealização e a da autodoação. 


\section{A regra de ouro e o sentido pré-ético da autorrealização}

O pensamento filosófico de Wojtyla tornou-se maduro com a obra Pessoa e ação, Osoba i czyn, e angariou alguns elogios e muitas críticas ao longo de quatro décadas. Dividida em quatro partes, Wojtyla discute aí quatro grandes problemas que são abordados a partir de um método ao mesmo tempo fenomenológico e metafísico-personalista, ${ }^{2}$ conforme se pode evidenciar em cada uma dessas partes:

1) Consciência e eficiência, a primeira parte da obra trata da pessoa e da ação sob o aspecto da consciência e a análise da eficiência a partir do dinamismo humano. A consciência é entendida como a função intelectual do homem. Em oposição à tendência fenomenológica, a consciência não se identifica com o sujeito, ao contrário, este é a base da consciência. Este é o elemento de caráter mais metafísico presente na obra.

O método fenomenológico, por outro lado, permite apontar que a consciência tem duas funções: a refletente e a reflexiva. Chega-se a estas funções por um processo de redução, termo que deriva de reducere, isto é, de reconduzir. Neste caso, trata-se de reduzir um fenômeno a seu fundamento. Já nesta primeira abordagem, deve entrever-se o fundamento da consciência no sujeito, confirmando, assim, o elemento metafísico antes aludido. Destarte, a manifestação do sujeito enquanto pessoa é descrita a partir de três características: a transcendência, a integração e a participação, que compõem, respectivamente, os três capítulos seguintes do livro.

2) A transcendência da pessoa na ação é atingida pelas descrições da estrutura pessoal da autodeterminação e realização. Entende-se transcendência no sentido existencial: ultrapassamento de uma situação. E o autor indica-lhe dois tipos: a horizontal, isto é, o ultrapassamento de um sujeito em direção a um objeto nos atos intencionais do conhecer e do querer; e a vertical, que é a transcendência da pessoa na ação. Esta é a transcendência que interessa à obra. É a transcendência do agir, é a transcendência em direção à verdade sobre o bem, a verdade em sentido axiológico. Como não perceber aqui a presença das filosofias de Kant e

2 O personalismo de Wojtyla tem uma conotação distinta da filosofia inaugurada pelo movimento Esprit, liderado por Emmanuel Mounier. Para Mounier, a pessoa é o referencial primário fundante do filosofar. Num outro gênero de personalismo, a pessoa pode ser entendida, em sentido metafísico, à maneira tomista; no sentido de existência, à maneira dos existencialistas; e, enfim, no sentido aristotélico de substância. Esta é a tendência do personalismo no sentido lato, conforme observa o primeiro tradutor italiano da obra de Wojtyla, o filósofo Armando Rigobello: "A pessoa não justifica especulativamente o quadro metafísico mas é aí justificada. Onde, ao contrário, assume o papel de critério fundante é o âmbito da ação moral e, às vezes, no âmbito da atitude política e educativa" (RIGOBELLO, A., "Il personalismo comunitario de "Esprit" ", Quaderno Filosófico, 8 (1983), p. 49). 
de Nietzsche? Todas as duas baseadas numa filosofia da ação. A primeira interessada na restauração das possibilidades metafísicas a partir da ética. O segundo visando à criação de valores a partir do sujeito reduzido à vontade.

3) A terceira parte trata da integração da pessoa na ação. Por integração, entende-se a manifestação da unidade a partir da multiplicidade, de modo particular as ativações da natureza, do corpo e da psique. Essa integração tem três níveis: o atual, o habitual e o potencial, que, por sua vez, explicam a unidade dinâmica dos estratos do homem: o somático, o psíquico e o espiritual.

A integração, exatamente como aspecto complementar em relação à transcendência da pessoa no ato, diz-nos que a relação entre alma e corpo ultrapassa todos os limites que encontramos na experiência, que é mais profunda do que eles e mais fundamental. E talvez nisso consiste a verificação, mesmo que indireta, da afirmação que a realidade da alma, como a da sua relação com o corpo, só possa ser expressa adequadamente na metafísica. ${ }^{3}$

4) Pessoa e participação: esboço de uma teoria da participação. $O$ homem age com os outros. Trata-se da transformação da comunidade a partir da pessoa, com todos os elementos indicados até aqui. Apresenta-se, aqui, o meio termo entre o individualismo e o totalitarismo.

Finalmente, Karol Wojtyla dedica as últimas páginas desta última parte da obra ao sentido pré-ético da regra de ouro enquanto regra de amor ao próximo. Não o faz com a intenção de adentrar nos terrenos da ética, nem no conteúdo propriamente ético e objetivo do mandamento, nem no significado ético do amor. Ao contrário, circunscreve sua análise à intenção de apreender um conteúdo pressuposto e indireto no mandamento que se refere ao "próximo como a ti mesmo". Com efeito, segundo o autor, há um sistema específico de referência pressuposto pelo mandamento evangélico na ideia de "próximo" e na justaposição do "próximo" ao "si mesmo". O conteúdo indireto do mandamento confirmaria que o sistema de referência centrado no próximo tem um significado superior, fundamental e pleno para o "si mesmo", para a pessoa humana, em todo o seu atuar e existir junto com os outros.

Para entender essa particular aproximação ao mandamento evangélico, é preciso recordar os pressupostos e as principais conclusões da quarta e última parte de Pessoa e Ato. Em primeiro lugar, a quarta parte é

3 WOJTYLA, K. Persona e atto. Milão: Bompiani , 2001, p. 609. Com exceção das obras já traduzidas ao português, todos os textos aqui citados em português são traduções dos autores. 
dedicada à noção mais geral de participação. O enfoque personalista de Karol Wojtyla baseia-se na convicção de que ser pessoa significa ser capaz de participação e de realizar-se mediante a participação. Embora o ser pessoa seja anterior à ação e à participação, e, portanto, a pessoa (e seu valor) seja anterior e mais fundamental do que o valor da ação e da participação, ${ }^{4}$ o personalismo assume como premissa que a pessoa manifesta-se a si mesma em suas ações. ${ }^{5}$ Assim sendo, como a ação constitui um momento da manifestação da pessoa e de seu valor pessoal, assim também a participação, ou seja, o ser, o viver e o agir junto com outros manifestam de modo mais especial a dimensão intersubjetiva da pessoa humana e a dinâmica de sua autorrealização ${ }^{6}$ na vida comunitária. ${ }^{7}$

Em segundo lugar, sustenta que a participação é uma característica não só do atuar junto com os outros, mas também é uma propriedade da pessoa, que tem a capacidade de atuar junto com os outros, não cessando de ser ela mesma e não cessando de realizar a si mesma em seus próprios atos $^{8}$. Isso significa que a pessoa humana, quando atua junto com outras pessoas, conserva tudo o que é resultado de sua autodeterminação e atuação em comum e, ao mesmo tempo, realiza o valor personalista de sua própria ação. ${ }^{9}$ Com efeito, a realização da ação pela pessoa, que é sua causa eficiente, é em si mesma um valor fundamental, denominado de valor personalista ou pessoal da ação. ${ }^{10}$

4 WOJTYLA, K. Persona y acción. Madrid: BAC de La Editorial Católica, 1982a, p. 310

5 Essa premissa do personalismo wojtyliano depende do princípio segundo o qual o agir segue e manifesta o ser (agere sequitur esse). Esse princípio é o que justificaria a defesa da dignidade da pessoa humana, uma vez que tanto a estrutura quanto a dinâmica do agir humano manifestariam a estrutura e o dinamismo da própria pessoa humana, da unicidade e dignidade do seu próprio ser. Para uma análise comparativa da noção de dignidade da pessoa humana em Tomás de Aquino e Wojtyla, confira Aguas (2009). Sobre a importância do conceito de "unicidade da pessoa humana" em Wojtyla, confira Colosi (2008).

6 O princípio da autorrealização poderia ser assim enunciado: a pessoa que executa a ação, por sua própria autodeterminação, realiza-se a si mesma nela. Realizar-se, por sua vez, significa atualizar as potencialidades da pessoa e levar à plenitude a estrutura do ser humano, que lhe é característica por sua personalidade e também pelo fato de ser alguém e não meramente algo.

7 A vida comunitária não deve ser entendida como o simples resultante da pluralidade de sujeitos coexistentes, mas sim em relação à unidade específica dessa pluralidade, dada seja na ordem da atuação em comum seja ainda na ordem do ser em comum, ainda que tal ser e agir em comum perfaça sempre uma ordem acidental em relação às pessoas, que são os únicos sujeitos realmente subsistentes e atuantes (Cf. WOJTYLA, K., "The person: subject and community". The Review of Metaphysics, v. 33, n. 2 (1979), p. 289).

8 WOJTYLA, Karol. "Participation or alienation?". Analecta Husserliana, 6 (1977), p. 70; “The person: subject and community". The Review of Metaphysics, 33, 2 (1979), p. 288; Persona y acción. Madrid: BAC de La Editorial Católica, 1982a, p. 314.

9 WOJTYLA, K. Persona y acción. Madrid: BAC de La Editorial Católica, 1982a, p. 315.

10 O valor personalista ou pessoal da ação é, para Wojtyla, intrínseco à mesma realização da ação pela pessoa humana, na medida em que tal atuação é conforme ao que o próprio agente é em sua autodeterminação. Ademais, o valor é personalista porque a pessoa que realiza a ação realiza-se a si mesma nela (Cf. WOJTYLA, K., Persona y acción. Madrid: BAC de La Editorial Católica, 1982a, p. 311). 
Para Wojtyla, ${ }^{11}$ o valor personalista da ação não deve ser confundido com o valor moral da ação, já que este último difere do primeiro por ser referente a uma norma objetiva. O valor personalista da ação, que se relaciona com a realização da ação pela pessoa e com a realização da pessoa pela ação, é a origem e base do conhecimento do valor da pessoa e dos valores próprios da pessoa.

Em terceiro lugar, a teoria da participação procura evidenciar que o ser e o atuar junto com os outros não constitui um novo sujeito de atuação, mas sim introduz novas relações (acidentais) entre as pessoas que são os sujeitos reais e verdadeiros do atuar. Em quarto lugar, a teoria da participação procura objetivar a norma subjetiva da participação, ou melhor, a aspiração inerente a cada pessoa em sua busca de autorrealização. Essa norma (subjetiva) estará na base de todo valor personalista da participação e de todo valor moral objetivo de que trata a ética.

Para entender esses dois últimos passos da teoria wojtyliana, é preciso recordar que o ser membro de uma comunidade não deve ser identificado com a própria participação no ser e no atuar junto com os outros. Afinal, a pessoa pode ser membro de uma comunidade e, não obstante, não ser partícipe dela, por estar alienado nela e por ela.

Para exemplificar esse ponto de sua teoria, Wojtyla recorre ao seguinte exemplo: um grupo de estudantes que assiste a uma conferência forma uma comunidade de atuação. Cada estudante é um membro da comunidade de atuação que, neste caso, pode ser considerada objetivamente pela busca coletiva dos mesmos fins. Na conferência, os estudantes procuram aprender algo em relação aos problemas e às soluções que constituem o tema da conferência, que, por seu turno, pode fazer parte do plano de estudos e do curso. Essa comunidade objetiva de fins contribui para objetivar a comunidade de atuação enquanto tal. ${ }^{12}$ Se é verdade que a comunidade de atuação pode ser entendida em sua dimensão objetiva pelos fins que perseguem coletivamente, também é verdade que subjetivamente seus membros podem ou não participar dela. Restaria saber, então, se a pessoa, que é membro de uma comunidade objetiva de atuação, em sua atuação comunitária pode executar verdadeiras ações personalistas e realizar a si mesmo nelas. Essa execução e realização estão determinadas pela participação. ${ }^{13} \mathrm{Em}$ síntese, no âmbito da esfera do ser e do atuar junto com os outros, uma comunidade pode permanecer no nível objetivo sem jamais atingir o nível

11 WOJTYLA, K. Persona y acción. Madrid: BAC de La Editorial Católica, 1982a, p. 309-310).

12 WOJTYLA, K. Persona y acción. Madrid: BAC de La Editorial Católica, 1982a, p. 326.

13 WOJTYLA, K. Persona y acción. Madrid: BAC de La Editorial Católica, 1982a, p. 327. 
subjetivo da participação, que pressupõe a autodeterminação ${ }^{14}$ pessoal dos fins comuns e do bem comum à pessoa e à comunidade. ${ }^{15}$

Quando consideramos esse momento, vemos que o bem comum não consiste unicamente no objetivo da atuação comum executada por uma comunidade ou grupo; em realidade consiste também, e inclusive primeiramente, no que de alguma maneira condiciona e inicia nas pessoas que atuam juntas sua participação, e, por isso mesmo, desenvolve e configura nelas uma comunidade subjetiva de atuação. ${ }^{16}$

Em Pessoa e Ato, o conceito de participação integra as reflexões prévias do autor sobre a autorrealização. Até mesmo o conceito pré-ético de participação, enquanto atuação junto com os outros, segundo as mais diversas, complexas e ricas formas de relações comunitárias e sociais, é aqui entendido como orbitando em torno de "si mesmo". A pessoa sempre permanece dentro de sua própria órbita, de sua própria e irredutível subjetividade, quando é e atua junto com os outros. E é justamente porque permanece dentro de sua própria órbita que a realização de si mesmo é a realização de seu valor personalista/pessoal.

Entretanto, a liberdade (autodeterminação) de atuar junto com os outros e de buscar a sua própria realização pode dar origem tanto às atitudes autênticas quanto às inautênticas. Novamente, deve-se ressaltar que tais atitudes não são definidas a partir de uma ordem e de uma avaliação estritamente ética, mas sim pré-ética, pois dizem respeito à norma e ao valor subjetivo da ação "junto com os outros". Nesse horizonte, a autodeterminação revela-se como pressuposta tanto pelas atitudes autênticas, fundadas na participação, quanto pelas atitudes inautênticas, resultantes da alienação.

O que diferencia as atitudes autênticas das inautênticas não é a liberdade ou não de atuar junto com os outros, mas sim ao modo atual e concreto de executá-las em relação ao outro ser humano, a um

14 Em Pessoa e Ato, Wojtyla define o conceito de "autodeterminação" após uma descrição fenomenológica da ação caracterizada pela experiência da eficácia, ou seja, pela consciência do agente como causa de mudanças exteriores bem como simultaneamente como causa de mudanças interiores. Isso significa que toda ação que procede da pessoa humana retorna sobre ela. E é justamente esse retornar sobre si mesmo que faz da ação uma fonte de realização do valor personalista. A autodeterminação consiste tanto na experiência da determinação disto ou daquilo pela pessoa que age quanto na experiência de ser determinado pela sua própria ação. Para Wojtyla, uma das razões da pessoa ser "um fim em si mesmo" é justamente a capacidade de autodeterminação.

15 Há, assim, para Karol Wojtyla, um duplo sentido para o bem comum: 1) o primeiro e mais importante, o subjetivo, que é relacionado à participação pessoal enquanto propriedade e qualidade da pessoa e do seu atuar em comum; 2) o segundo, condicionado pelo primeiro, é o objetivo que se relaciona aos fins almejados pela comunidade de atuação.

16 WOJTYLA, K. Persona y acción. Madrid: BAC de La Editorial Católica, 1982a, p. 329. 
"outro-eu". Como as atitudes autênticas podem ser distorcidas e tornarem-se inautênticas nas mais diversas situações concretas, a pedra de toque para discernir umas das outras é a subordinação dinâmica à verdade, que resulta essencial à transcendência da pessoa na ação. ${ }^{17}$ Essa subordinação das atitudes ao verdadeiro valor da pessoa é refletida na consciência reta da pessoa que age junto com os outros.

O ato de consciência (...) deixa-nos clara esta relação causal da pessoa com o bem ou o mal moral. Concretamente, a encontramos no conteúdo da experiência vivida, isto é, no fato de que a convicção acerca do bem obrigue a realizá-lo e no fato de que a convicção acerca do mal obrigue a não realizá-lo. ${ }^{18}$

A consciência reta, para Wojtyla, é sempre "juiz supremo da autenticidade das atitudes humanas no que se refere ao ser e ao atuar 'junto com os outros'". ${ }^{19}$ Mas, qual é o verdadeiro valor personalista do outro com o qual e sobre o qual a pessoa age? Assim como a ação manifesta o valor personalista do agente, a participação, enquanto ação junto com os outros, manifesta o valor personalista do outro. Tal manifestação do valor personalista supõe, portanto, a descoberta de um ulterior sentido da participação, além daquele exposto até aqui. Com efeito, a participação, pressuposta pelas atitudes autênticas, ${ }^{20}$ é justamente aquela na qual cada pessoa humana, dentro de sua própria órbita, é chamada a vivenciar o outro ser humano como um "outro-eu", isto é, é "chamada a participar em sua humanidade, concretizada em sua pessoa, de forma semelhante ao modo como a minha humanidade está na minha pessoa". ${ }^{21}$

Eis o segundo sentido da participação em Pessoa e Ato, que complementa o primeiro e oferece a orientação axiológica devida ao outro ser humano. O primeiro sentido, com efeito, afirmava somente que a participação é uma propriedade da pessoa humana, enraizada na capacidade de ser e atuar junto com os outros sem cessar de ser ela mesma e de realizar a si mesma mediante suas próprias ações. O segundo

17 WOJTYLA, K. Persona y acción. Madrid: BAC de La Editorial Católica, 1982a, p. 336.

18 WOJTYLA, K., Max Scheler e a ética cristã. Curitiba: Editora Universitária Champagnat, 1993, p. 114.

19 WOJTYLA, K. Persona y acción. Madrid: BAC de La Editorial Católica, 1982a, p. 336.

20 Em Pessoa e Ato, Karol Wojtyla desenvolve sua reflexão em torno das seguintes atitudes autênticas: 1) solidariedade, que significa uma disposição constante a aceitar e a realizar a parte que lhe corresponde numa comunidade, como consequência da condição de membro dessa comunidade particular; 2) a oposição justificada, que é a busca de seu lugar próprio na comunidade na realização do bem comum e no pleno direito à participação de seus membros; 3) o diálogo, que promove o bem comum em termos dinâmicos e não estáticos. (Cf. WOJTYLA, K. Persona y acción. Madrid: BAC de La Editorial Católica, 1982a, p. 331-335).

21 WOJTYLA, K., 1977, p. 66; "The person: subject and community". The Review of Metaphysics, 33, 2 (1979), p. 288-289. 
sentido, por sua vez, implica a relação entre a dinâmica da autorrealização e a dinâmica da participação na humanidade de outra pessoa, seja enquanto membro de uma comunidade seja enquanto próximo. ${ }^{22}$

A participação na humanidade de outra pessoa manifesta o seu verdadeiro valor personalista. Tal participação não deve, segundo Wojtyla, ser entendida como a participação na ideia abstrata da humanidade ou em uma de suas instanciações, mas sim como a participação no ser pessoal de cada ser humano, em sua unicidade e irredutibilidade. A consideração de uma pessoa humana como indivíduo membro de uma espécie, e não como sujeito pessoal, único e irredutível, está na base de toda relação alienante e das atitudes inautênticas, que ignoram, diminuem ou impedem a manifestação do verdadeiro valor personalista do outro.

A alienação, pressuposta pelas atitudes inautênticas, ${ }^{23}$ é justamente aquela na qual cada pessoa humana, dentro de sua própria órbita, não se realiza mediante a participação na humanidade do outro. A alienação denota aquela situação em que uma pessoa humana não é capaz de vivenciar um outro ser humano como "outro eu", através do enfraquecimento, da deformação e até mesma da aniquilação em si mesmo da participação na humanidade de outros. Em geral, a alienação pode ocorrer: 1) quando o ser humano, para ser si mesmo e determinar livremente seus próprios atos, não participa da humanidade de outro ser humano como um "outro-eu"; 2) quando a comunidade de atuação, para ser si mesma e determinar a si mesma os seus próprios fins, impede e até mesmo destrói a capacidade de cada um dos seus membros de, atualmente, participar na humanidade não só dos seus próprios membros, mas também na humanidade do próximo.

Essa última conclusão supõe a distinção entre o consócio e o próximo. De acordo com Wojtyla, toda análise da pessoa enquanto ser capaz de atuar junto com os outros pode ser feita a partir de dois pontos de vista ou sistemas de referência distintos, porém complementares e interdependentes. Cada pessoa humana pode pertencer a distintas comunidades e sua condição de membro de cada uma delas perfaz um sistema específico de referência, designado com a noção de "consócio". Por sua vez, há um outro sistema mais universal de referência que é

22 WOJTYLA, K. "The person: subject and community". The Review of Metaphysics, 33, 2 (1979), p. 288.

${ }^{23}$ Em Pessoa e Ato, Karol Wojtyla desenvolve sua reflexão em torno das seguintes atitudes inautênticas: 1) conformismo, que significa o servilismo, ou seja, a atitude de obediência ou resignação em uma forma específica de passividade que faz a pessoa ser o sujeito do que ocorre em vez de ser seu autor; 2) evasão, que é a ausência de compromisso com a participação na comunidade e o comprometimento com seus fins (Cf. WOJTYLA, K. Persona y acción. Madrid: BAC de La Editorial Católica, 1982a, p. 336-340). 
designado com a noção de "próximo". Tanto a noção de "membro de uma comunidade" quanto a de "próximo" são intimamente relacionadas, mas marcam distintas possibilidades e tendências dentro da participação pessoal. Em verdade, cada um desses sistemas de referência comporta uma mudança de perspectiva em relação à própria participação. E essa mudança é pressuposta indiretamente, segundo Wojtyla, pelo mandamento evangélico.

Num primeiro momento, pode parecer que cada ser humano, enquanto membro de uma comunidade, tem por próximo os demais membros da mesma comunidade. Em torno de cada membro de uma comunidade haveria, assim, um "círculo dos próximos", em relação ao qual há próximos mais próximos do que outro ${ }^{24}$. A ideia de próximo, enquanto membro mais próximo dentre os membros de uma mesma comunidade, valorizaria em cada homem aquilo que ele é enquanto membro de uma comunidade. Há, não obstante, um outro horizonte ou sistema de referência ao próximo que não está condicionado aos limites intrínsecos do ser membro de uma comunidade. Esse novo sistema de referência ao próximo não condicionado ao ser membro de uma comunidade é o que se dirige à pessoa e ao seu valor enquanto tal.

A distinção entre o "próximo" e o "membro de uma comunidade" é assim explicada por Karol Wojtyla:

\begin{abstract}
A ideia de 'próximo' nos obriga não só a reconhecer, mas também a valorar aquilo que dentro do homem é independente de sua condição de membro de qualquer comunidade; obriga-nos a observar e apreciar nele algo que é muito mais absoluto. A ideia de próximo está intimamente relacionada com o homem enquanto tal e com o mesmo valor da pessoa, prescindindo de todas as suas relações com uma ou outra comunidade ou com a sociedade. A ideia toma em consideração unicamente a humanidade do homem - essa humanidade que é possessão de todo homem igual a si mesmo. Por isso, constitui a base mais ampla da comunidade ${ }^{25}$.
\end{abstract}

Ao referir-se ao "próximo", a regra de ouro presume uma perspectiva transcendente, universal e concreta sobre o ser humano. Mais transcendente, pois o ser próximo transcende em seu valor pessoal ao ser membro de uma comunidade. Mais universal porque se estende a todo ser humano enquanto tal e não só aos membros de uma ou outra comunidade. Mais concreta por afirmar unicamente a humanidade de cada homem, ou seja, o seu valor único e irredutível enquanto ser e pessoa humana.

${ }^{24}$ WOJTYLA, K. Persona y acción. Madrid: BAC de La Editorial Católica, 1982a, p. 341.

25 WOJTYLA, K. Persona y acción. Madrid: BAC de La Editorial Católica, 1982a, p. 341-342 
Para Karol Wojtyla, há evidente precedência do valor do próximo sobre o valor do membro de uma comunidade. Mas, essa precedência não deve ser entendida como sinal de oposição ou contradição, já que "ser próximo" e "ser membro de uma comunidade" são duas realidades interdependentes que marcam dois valores intrínsecos à pessoa humana, ameaçados constantemente pela alienação, que nada mais é do que a desconsideração ou mesmo negligência da profundidade da participação na humanidade do outro, indicada, sobretudo, pela ideia de "próximo". Por essa razão, o preceito áureo tem um caráter profundamente comunitário, por ser "expressão do que é necessário para que se forme uma comunidade" e por "destacar, acima de tudo, o que é necessário para que uma comunidade seja realmente humana". ${ }^{26}$

Os dois sistemas de referência, o do próximo e o do consócio, conservam entre si uma subordinação e não uma contradição, de tal forma que qualquer imposição de um sistema sobre outro resultaria inadmissível e perigosa para Karol Wojtyla. Se a participação na comunidade for a limitação da participação na humanidade dos outros ou se a participação na humanidade dos outros for um impedimento para a participação na comunidade, então, há um perigo de distorção da participação, que pode converter-se em alienação.

A essência real desta alienação parece ser revelada no mandamento 'amarás'. A alienação do homem em relação aos demais homens procede do esquecimento ou descuido dessa profundidade real de participação que se indica com a palavra próximo e na ideia de interrelação e intersubordinação dos homens em sua humanidade, o princípio mais fundamental de toda comunidade real. ${ }^{27}$

Para proteger as comunidades reais dos homens dos perigos da alienação, Wojtyla propõe converter o sistema de referência ao próximo como critério último para o desenvolvimento da coexistência e da cooperação dos homens nas mais diversas e complexas relações intracomunitárias. Esse estreita união entre pessoa e comunidade entendida sob a ótica da participação, como justa posição entre o "si mesmo" e o seu "próximo" é, antes de tudo, uma tarefa real cuja medida é o mandamento do amor:

O mandamento do amor constitui também a medida das tarefas e exigências com que deve enfrentar-se todo homem - todas as pessoas e todas as comunidades - para que se converta em uma realidade todo o bem contido no atuar e no existir 'junto com os outros'. ${ }^{28}$

26 WOJTYLA, K. Persona y acción. Madrid: BAC de La Editorial Católica, 1982a, p. 345.

27 WOJTYLA, K. Persona y acción. Madrid: BAC de La Editorial Católica, 1982a, p. 346.

28 WOJTYLA, K. Persona y acción. Madrid: BAC de La Editorial Católica, 1982a, p. 347. 
Em Participação ou Alienação, Wojtyla ${ }^{29}$ corrobora que o mandamento do amor é uma medida das tarefas e das exigências humanas porque "todo ser humano deve constantemente considerar como um dever a atual participação na humanidade de outra pessoa, isto é, a vivência de um outro como um 'eu', como uma pessoa". Essa medida implícita à regra de ouro, tal como expressa no mandamento evangélico, é uma norma pessoal de aspiração (subjetiva) e não um dever ético e moral (normas objetivas), já que pertence à própria dinâmica pessoal da autorrealização mediante a aspiração à participação. Para Wojtyla, toda consideração na ordem estritamente ética assumirá como base axiológica a descoberta do valor personalista da participação na humanidade do próximo para a realização de si mesmo.

A teoria da participação não só procura explicar o que é a atuação do homem "junto com os outros" e como se realiza subjetiva e objetivamente a pessoa que atua "junto com os outros", mas também aponta, ainda que indiretamente, o caráter normativo e subjetivo do princípio da participação. ${ }^{30} \mathrm{~A}$ transição do fato da participação ao valor normativo e subjetivo da participação dá-se pela consideração das aspirações à participação que marcam profundamente a experiência vivida dos homens que são e atuam junto com outros. Assim esclarece Wojtyla o conteúdo pré-ético e normativo da participação:

Porque si, ao atuar, junto com os outros, o homem pode realizar-se
segundo este princípio, nesse caso, por um lado, todos deveriam aspirar
essa forma de participação, que lhes fará possível, na atuação junto com
os outros, realizar o valor personalista de sua própria ação. Por outro
lado, toda comunidade de atuação ou toda cooperação humana deveria
ser orientada de forma que fosse possível que a pessoa, que permanece
dentro de sua órbita, se realizasse a si mesma mediante a participação. ${ }^{31}$

O itinerário de Karol Wojtyla em Pessoa e Ato poderia levar o leitor a pensar que a busca humana pela autorrealização, fundada na autodeterminação do valor personalista de suas próprias ações, exclui a disposição para a participação na humanidade do próximo. Afinal, toda pessoa que age o faz sempre centrada em sua própria órbita. Entretanto, Karol Wojtyla sustenta explicitamente que não só cada pessoa age em busca de sua autorrealização, mas também que tal autorrealização pressupõe a disposição e a atual e efetiva participação de si mesmo na humanidade do próximo. Isso só pode ser possível porque, para Karol Wojtyla, o "ser

\footnotetext{
29 WOJTYLA, K.. "Participation or alienation?". Analecta Husserliana, 6 (1977), p. 67

30 WOJTYLA, K. Persona y acción. Madrid: BAC de La Editorial Católica, 1982a, p. 317-318.

31 WOJTYLA, K. Persona y acción. Madrid: BAC de La Editorial Católica, 1982a, p. 318.
} 
centrado em sua própria órbita" não é o "ser fechado em sua própria órbita", mas sim o ser que deve por si mesmo autodeterminar-se.

Doravante, a descoberta de sua própria e pessoal humanidade mediante a participação na humanidade pessoal do próximo será designada por "lógica da autorrealização". Essa expressão, inexistente em Karol Wojtyla, será utilizada, aqui, para designar que nem toda autodeterminação pertence à lógica da autorrealização que supõe a disposição e a aspiração pessoal à participação. Afinal, pode haver uma autodeterminação da pessoa que, em razão da alienação, não conduz à realização de si mesmo. Por outro lado, toda autodeterminação que efetivamente pode conduzir à autorrealização é necessariamente, para Wojtyla, uma afirmação não só de si mesmo, em sua própria humanidade, mas, sobretudo, uma afirmação do outro em sua própria humanidade, no que nele há de único e irredutível. E é por essa razão que a lógica da autorrealização não é a lógica de uma liberdade enclausurada, mas sim de uma liberdade que manifesta a humanidade da pessoa que age mediante a atual e efetiva participação na humanidade do outro, seu próximo.

\section{A regra de ouro e o sentido ético da autorrealização}

A primeira parte desse estudo concentrou-se em entender o sentido pré-ético do mandamento do amor, ou melhor, o sentido da justaposição do próximo ao si mesmo. Essa justaposição tem suas raízes na própria dinâmica da autorrealização na medida em que cada pessoa que age junto com os outros aspira a ser reconhecida em sua própria humanidade e, portanto, aspira a ser próximo mais do que um membro de uma comunidade. Essa aspiração subjetiva que está na base do valor personalista das ações só pode ser atual e efetiva quando cada pessoa não só aspirar subjetivamente a ser próximo, ou seja, a ser afirmada em sua própria humanidade, mas, sobretudo, participar, subjetiva e objetivamente, da humanidade do próximo. Eis a razão pela qual a regra áurea justapõe o próximo ao si mesmo.

Essa singular dinâmica da autorrealização, frequentemente ameaçada pela alienação, é o drama pessoal (dramatis persona) vivido interiormente como oposição entre os valores pessoais e comunitários (em sentido pré-ético) e as obrigações morais. ${ }^{32}$ A realidade existencial do drama

32 Como se sabe, Karol Wojtyla define a Ética como a ciência normativa e não descritiva do bem e do mal moral. É tarefa específica da Ética, segundo o autor, definir as normas morais, expressá-las em juízos ou proposições práticas sobre o que é o bom ou o mau, e, sobretudo, proporcionar as razões e justificativas desses juízos. Em síntese, as normas, para Karol Wojtyla, outorgam à Ética seu caráter especificamente científico. (Cf. WOJTYLA, K. Mi visión del hombre. Espanha: Palabra, 2005, p. 25-26; p. 35). 
do homem que se faz pessoa mediante sua própria autodeterminação é assim expressa por Karol Wojtyla: "Fora do drama, o homem não pode realizar-se como pessoa. Em realidade, parece que a realização é tanto mais madura quanto mais profundo e radical é o drama dos valores e das obrigações dentro do homem". 33

A mediação entre o valor e a obrigação é uma tarefa e um desafio pessoal. É preciso que cada um faça a sua própria e singular mediação entre os valores e as obrigações morais para converter, tal qual um círculo virtuoso, a obrigação moral em valor pessoal, condição sine qua non da autorrealização. Uma das formas mais instigantes de participar dessa tarefa e desse desafio é tomando consciência da força atrativa do valor tornado obrigação no mandamento evangélico do amor. Essa tomada de consciência não está restrita aos cristãos, que já previamente assumem a fórmula evangélica da regra áurea como um dom tornado obrigação. ${ }^{34}$

Os princípios revelados, em todo caso, não se opõem ao intelecto, ainda que o intelecto não seja por si só capaz de formulá-los. Por exemplo, embora o mandamento do amor aos inimigos constitua um princípio moral difícil para o intelecto, não obstante, o homem, seguindo precisamente a razão, deve constatar toda a grandeza ética gravada neste princípio. ${ }^{35}$

A questão da mediação entre o valor e a obrigação em termos racionais e filosóficos ocupou de maneira especial as reflexões de Karol Wojtyla em Max Scheler e a Ética Cristã e igualmente em Amor e Responsabilidade. Em Max Scheler e a Ética Cristã ${ }^{36}$ o preceito áureo é a pedra de toque para o juízo de adequação entre a ética personalista de Max Scheler e a ética cristã, enquanto em Amor e Responsabilidade ${ }^{37}$ o mandamento do amor permite a crítica aos pressupostos e consequências éticas do utilitarismo.

Três questões principais servem aqui de orientação para o estabelecimento dos pressupostos filosóficos adequados à interpretação e à justificação da regra de ouro expressa no mandamento do amor. A primeira questão diz respeito à possibilidade do amor ser objeto de um mandamento. A segunda procura resolver em que consiste a natureza

33 WOJTYLA, K. Persona y acción. Madrid: BAC de La Editorial Católica, 1982a, p. 196

${ }^{34}$ Para Karol Wojtyla, ao menos os princípios mais importantes da moral estão naturalmente inscritos em cada pessoa humana, sem uma específica revelação por parte de Deus. Esses princípios são vinculantes por natureza para a consciência de cada homem que conhece sua existência. Assume, assim, a premissa clássica segundo a qual a natureza e a razão são sempre fontes de conhecimento (e não de criação) dos princípios e das normas morais (Cf. WOJTYLA, Karol, Mi visión del hombre. Espanha: Palabra, 2005, p. 37-38).

35 WOJTYLA, K., Mi visión del hombre. Espanha: Palabra, 2005, p. 32.

36 WOJTYLA, K. Max Scheler e a ética cristã. Curitiba: Editora Universitária Champagnat, 1993, p. 130-137.

37 WOJTYLA, K. Amor e Responsabilidade. São Paulo: Edições Loyola, 256 p., 1982b, p. 37-41. 
do ato de amor e concretamente do ato de amor moral. Enfim, a terceira busca saber se a experiência moral do amor é a experiência do valor ou do dever.

Quanto à primeira questão, Wojtyla recorda que, para Max Scheler, o amor não pode ser objeto de um mandamento, embora as fontes cristãs sustentem o contrário. Max Scheler defendeu a impossibilidade de o amor ser objeto de um mandamento em razão de seus pressupostos sobre o amor e sobre o dever moral. Com efeito, Scheler concebeu o amor como um ato puramente espontâneo, emocional, suscitado do interior e não do exterior, pelo qual a pessoa encontra e manifesta o mundo dos valores. Por sua vez, concebeu o mandamento ou o dever como uma imposição exterior contrária, portanto, à dinâmica interior e espontânea do amor. Em sua resposta, Wojtyla observa que: "embora 'mandar' signifique 'suscitar um dever a partir do exterior', não exclui que ao mesmo tempo surja do interior o ato que é objeto do mandado" (1993, p. 132-133).

Quanto à segunda questão, Wojtyla sustenta, novamente contra Scheler, que o ato de amor tem um sentido e uma natureza moral e objetiva. Com efeito, o amor não só provoca a manifestação de valores na experiência do sujeito pessoal do amor, mas qualifica moralmente o seu sujeito. Para Wojtyla, em todo ato de amor há uma relação causal eficiente da pessoa a respeito dos valores que ela realiza mediante o amor, seja por si mesma seja em relação a outro. Assim, se o amor é mandamento é justamente porque pode ser uma manifestação da causalidade eficiente e interior da pessoa que é capaz de amar e, mediante o amor, pode realizarse como pessoa. ${ }^{38}$

Enfim, a última questão permite Wojtyla resolver a oposição, pelo menos teoricamente, entre o valor e a obrigação. Com efeito, a experiência moral do amor é uma efetiva realização de valores, nos quais está contida a relação causal da pessoa com respeito aos mesmos valores. Mas, essa experiência do amor é moral justamente porque pode ou não ser conforme ao dever, que sendo suscitado pelo exterior (tal como a regra exterioridade nos evangelhos) encontra-se no umbral da consciência e de toda escolha interior, formal e pessoal do valor a ser realizado. A experiência moral do amor é a experiência, portanto, da conjunção entre o valor e o dever:

A conjunção deve realizar-se de tal modo que o amor culmine, de alguma maneira, na experiência do dever mediante uma 'percepção afetiva' mais

\footnotetext{
38 WOJTYLA, K. Max Scheler e a ética cristã. Curitiba: Editora Universitária Champagnat, 1993, p. 134-135. Essa segunda questão oferece ainda a oportunidade para Wojtyla realizar outra crítica a Scheler, que subordinaria o mandamento do amor ao seguimento de Cristo. Para Wojtyla (1993, p. 136), o mandamento do amor e o seguimento de Cristo são dois mandamentos eticamente diferentes, sendo o primeiro mais amplo e fundamental do que o segundo.
} 
plena do valor realizado; ao mesmo tempo, aquela realização do valor adquire cada vez maior força real com a experiência do dever. Assim, pois, estes dois fatores fundamentais da vida moral não se excluem no amor e sim se complementam mutuamente. A experiência profunda dos valores faz com que o dever se manifeste mais preciso e ativo, e, por seu lado, esta firme e ativa experiência do dever constitui a força peculiar de realização dos valores na experiência. ${ }^{39}$

Essa mesma tese da conjunção entre o amor e o dever, expressa no mandamento evangélico, é encontrada em Pessoa e Ato:

o melhor e mais completo dos exemplos de obrigação iniciada pelo valor em sentido positivo é e seguirá sendo o mandamento evangélico 'amarás'. Nesse caso, a obrigação é diretamente manifestada pelo valor, com todo o seu conteúdo intrínseco e toda sua força de atração. Mas o conteúdo atrativo de um valor se detém - por assim dizer - no umbral da interioridade da pessoa, o umbral erigido pela consciência, que comprova a veracidade do bem que se apresenta no valor; com esta prova é com o que se começa a obrigação. ${ }^{40}$

Se em Max Scheler e a ética cristã, o mandamento do amor é apresentado como síntese entre o valor do amor e o dever de amar, síntese essa que constitui, sobretudo, a experiência moral do amor, em Amor e Responsabilidade, o mandamento evangélico é justificado filosoficamente nos termos da norma personalista, que exclui as premissas da ética utilitarista. ${ }^{41}$

A norma personalista é expressa com dois conteúdos distintos e complementares entre si. Em sua primeira formulação, o conteúdo da norma é expresso negativamente nos seguintes termos: "a pessoa é um bem, o qual não está de acordo com a utilização, tendo em vista que não pode ser tratada como objeto de uso, portanto como um meio". Em sua segunda formulação, o conteúdo da norma é proposto positivamente: "a pessoa é um bem tal que só o amor se relaciona com ela própria e

39 WOJTYLA, K. Max Scheler e a ética cristã. Curitiba: Editora Universitária Champagnat, 1993, p. 137.

40 WOJTYLA, K. Persona y acción. Madrid: BAC de La Editorial Católica, 1982a, 194.

41 "Portanto, a genealogia dos meus estudos centrados no ser humano, na pessoa humana, é antes de mais nada pastoral. E é precisamente a partir da perspectiva pastoral, como em Amor e Responsabilidade, que formulei o conceito da norma personalista. Tal norma é a tentativa de traduzir o mandamento do amor na linguagem da ética filosófica." (JOÃO PAULO II, Cruzando o limiar da esperança. Rio de Janeiro: Ephraim Ferreira Alves 1994, p. 186.). Embora, na obra citada, Wojtyla fale de uma tentativa de traduzir o mandamento nos termos de uma norma ética filosófica, em Amor e Responsabilidade, ele já fala em fundamentar e justificar o mandamento nos termos de uma norma ética filosófica. Se há ou não uma diferença essencial entre uma e outra aproximação, ou seja, entre a simples tradução do mandamento e sua fundamentação, não me deterei aqui. 
plenamente"42. Em Amor e Responsabilidade, Karol Wojtyla sustenta explicitamente que o mandamento do amor diz "ama a pessoa", enquanto a norma personalista afirma que a "pessoa é um bem a respeito do qual só o amor constitui a relação própria e plenamente válida" ${ }^{43}$. Em termos filosóficos, portanto, o mandamento do amor só é universalmente válido quando assumido na perspectiva da norma personalista, já que nela se expressa a atitude de amor que é devida à pessoa quando essa é objeto da ação.

Se é verdade que a pessoa é tanto aquela que ama como aquela que é amada, não é menos verdade que nem todo amor permite a autorrealização e essa experiência vivida é a base de toda a reflexão ética sobre a relação entre o valor do amor e o dever de amar. Com efeito, o homem pode amar a si mesmo e a outro com uma "medida que abarca o homem em sua totalidade" 44 . Essa medida está contida nas palavras do mandamento ("como a ti mesmo"). Aliás, observa Wojtyla, "cada um só pode dar o que tem" e, portanto, "se alguém dá mais do que parece ter, é necessário constatar que, em realidade, tem mais do que parece ter". ${ }^{45}$ Por outro lado, o mandamento evangélico não proíbe que o homem queira mais para si, seja na esfera dos bens espirituais seja ainda na dos bens materiais. A única condição, medida e exigência proposta no mandamento é que cada um, que queira ou tenha mais para si, dê mais de si mesmo aos outros. Para Wojtyla, o amor, enquanto dom de si mesmo, constitui a fonte sempre renovada da riqueza interior do homem.

\section{Considerações finais}

No itinerário intelectual de Karol Wojtyla, aqui descrito em razão de sua interpretação da regra de ouro, é possível reconhecer a preocupação metodológica do autor em discernir o sentido pré-ético (ou fenomenológico) do sentido propriamente ético da regra. Se a interpretação desenvolvida até aqui está correta, essa preocupação metodológica está a serviço da tese antropológica segundo a qual a dinâmica da autorrealização é também a dinâmica da aspiração à participação na humanidade do próximo, manifestada de forma especial na dinâmica pessoal da autodoação. E se essa concepção antropológica for aceita, então, pode-se propor como critério teórico para a avaliação das normas morais a capacidade das regras objetivas integrarem e complementarem a realização do próximo com a realização de si mesmo.

42 WOJTYLA, K. Amor e Responsabilidade. São Paulo: Edições Loyola, 256 p., 1982b, p. 38.

43 WOJTYLA, K. Amor e Responsabilidade. São Paulo: Edições Loyola, 256 p., 1982b, p. 39.

44 WOJTYLA, K., Mi visión del hombre. Espanha: Palabra, 2005, p. 101.

45 WOJTYLA, K., Mi visión del hombre. Espanha: Palabra, 2005, p. 101. 
Desde Pessoa e Ato, Wojtyla sustentou tanto o caráter irredutível da subjetividade humana, que até mesmo em seu atuar junto com os outros permanece sempre dentro de sua própria órbita, quanto a capacidade da pessoa humana em participar da humanidade de outra. Isso revela o outro aspecto do filosofar de Wojtyla: uma aproximação do personalismo interpretado em sentido lato. Destarte, seu percurso foi marcado pela firme convicção de que o ser centrado em sua própria órbita não significa o ser enclausurado em relação à realidade do próximo. Ao contrário, "somente o que se possui também pode doar-se e doar-se desinteressadamente. E somente ao que se domina pode fazer uma oferta de si mesmo e, repetimos, uma oferta desinteressada". ${ }^{46}$

A força atrativa da regra de ouro consiste justamente no valor do dom pessoal de si como condição para a própria realização de si mesmo. Com efeito, a regra de ouro exorta o sujeito moral a avançar de si mesmo em direção ao próximo, postulando a passagem do valor e da norma (em sentido subjetivo ou personalista) de aspiração ao valor e à norma objetiva ou ética do amor, tal como formulada e postulada no princípio de doação de si mesmo ao próximo. Essa exortação acompanha todo o drama pessoal do sujeito moral, que vive concretamente o conflito entre os seus valores pessoais e as obrigações morais. Uma das formas mais instigantes de perpassar tal conflito, segundo Wojtyla, é através da tomada de consciência da força atrativa do valor tornado obrigação na regra de ouro, ou melhor, no mandamento do amor ao próximo.

Para Wojtyla, não resta dúvida de que o amor como dom de si mesmo é a atitude mais perfeita e moralmente válida em relação a outra pessoa quando essa é o objeto de ação. Nesse sentido, pode-se dizer que a regra de ouro, tal como expressa no mandamento evangélico, é também um impulso, expresso exteriormente como um dever, que pode e deve emergir sempre de dentro do sujeito pessoal do amor, de sua própria autodeterminação, em relação à pessoa do outro quando essa é o objeto de suas ações.

\section{Referências}

AGUAS, J. J. S. "The notions of human person and human dignity in Aquinas and Wojtyla". Kritike, 3 (2009), p. 40-60.

COLOSI, Peter. "The uniqueness of persons in the life and thought of Karol Wojtyla/ Pope John Paul II, with emphasis on his indebtedness to Max Scheler". In: MARDAS, Nancy (Org.). Karol Wojtyla's philosophical legacy. Washington, DC: CRVP, 2008.

46 WOJTYLA, K. "La estructura general de la autodecisión". In: Karol Wojtyla, El hombre y su destino. Espanha: Palabra, 1999, p. 183 
JOÃO PAULO II. Cruzando o limiar da esperança. Rio de Janeiro: Ephraim Ferreira Alves, 1994. 209p.

KALINOWSKI, Georges. "Edith Stein et Karol Wojtyla sur la personne". Revue Pholosophique de Louvain, 82, 56 (1984), p. 545-561.

MODRAS, Ronald. "The moral philosophy of Pope John Paul II". Theological Studies, 41, 1980, p. 683-697.

NEUSNER, J.; CHILTON, B. The Golden Rule: the ethics of reciprocity in world religions. London/New York: Continuum, 2008.

RIGOBELLO, Armando. "Il personalismo comunitario de 'Esprit'”. Quaderno Filosófico, 8 (1983), p. 47-72.

SALLES, S. S.; OLIVEIRA, M. M.; SILVA, J. A. do N. "Lei natural e regra de ouro em Tomás de Aquino". Aquinate, 15 (2011), p. 90-115.

SCHELER, Max. Formalism in Ethics and Non-Formal Ethics of Values: a new attempt toward the foundation of an ethical personalism. Illinois: Northwestern University Press, 1973.

SZOSTEK, Andrzej. "Karol Wojtyla's view of the human person". In: TISCHNEN, Jozef (Ed.). The philosophy of person: solidarity and cultural creativity. Washington, D.C.: CRVP, 1994. 186p.

WATTLES, Jeffrey. The Golden Rule. New York: Oxford University Press, 1996.

WOJTYLA, Karol. "Participation or alienation?". Analecta Husserliana, 6 (1977), p.61-73.

. "The person: subject and community". The Review of Metaphysics, 33, 2 $\overline{(1979)}$, p. 273-308.

. Persona y acción. Madrid: BAC de La Editorial Católica, 1982a. 350p.

. Amor e Responsabilidade. São Paulo: Edições Loyola, 1982b. 256p. 1993. 183p.

. Max Scheler e a ética cristã. Curitiba: Editora Universitária Champagnat,

. "La estructura general de la autodecisión". In: Karol Wojtyla, El hombre y su destino. Espanha: Palabra, 1999. 256p.

Persona e atto. Milão: Bompiani, 2001. 765p.

Mi visión del hombre. Espanha: Palabra, 2005. 368p.

\section{Endereço postal:}

Pontifícia Universidade Católica do Rio de Janeiro - PUC-Rio

Rua Marquês de São Vicente, 225 - Gávea

Cx. Postal 38097

22451-900 Rio de Janeiro, RJ, Brasil

Data de recebimento: 30/04/2013

Data de aceite: 17/07/2013 